\title{
Rádio Federal FM e as adaptações no ofício de radialista frente às mudanças tecnológicas (1980-2017)
}

\author{
Radio Federal FM y las adaptaciones en el oficio de radialista frente a los \\ câmbios tecnológicos (1980-2017) \\ Radio Federal FM and the adaptations in the broadcaster role considering \\ the technological changes (1980-2017)
}

\author{
Silvana de Araújo Moreira ${ }^{1}$
}

\begin{abstract}
Resumo
A Rádio Federal FM está vinculada à Universidade Federal de Pelotas e foi a primeira emissora de caráter educativo a funcionar em canal de Frequência Modulada no Rio Grande do Sul. Em seus 36 anos de existência, uma breve história institucional é contada no endereço eletrônico da emissora. A pesquisa realizada para este artigo é a primeira fase de um trabalho historiográfico que pretende abranger a história da Rádio a partir do ofício de radialista e das transformações pelas quais passou para sobreviver às novas tecnologias, bem como o impacto no cotidiano desses profissionais que fizeram parte da história da Federal FM. O estudo apresentado utilizará principalmente a metodologia da história oral, em sua vertente temática, além de fontes documentais e impressas. Os depoimentos, narrativas e memórias daqueles que participaram e/ou participam do conjunto de profissionais da emissora permitem a revelação de alguns elementos da história e da evolução do rádio no contexto da região sul do estado.
\end{abstract}

Palavras-Chave: Federal FM, história oral, radialistas, rádio.

\section{Resumen}

La Radio Federal FM está vinculada a la Universidad Federal de Pelotas y fue la primera emisora de carácter educativo a funcionar en canal de Frecuencia Modulada en Rio Grande do Sul. En sus 36 años de existencia, una breve historia institucional es contada en el sitio web de la emisora. La investigación realizada para este artículo es la primera fase de un trabajo historiográfico que pretende abarcar la historia de la Radio a partir del oficio de radialista y de las transformaciones por las que pasó para sobrevivir a las nuevas tecnologías, así como el impacto en el cotidiano de esos profesionales que formaron parte de la historia de la Federal FM. El estudio presentado utilizará principalmente la metodología de la historia oral, en su vertiente temática, además de fuentes documentales e impresas. Los testimonios, narrativas y memorias de los que participan y participaron del conjunto de profesionales de la emisora permiten la revelación de algunos elementos de la historia y de la evolución del radio en el contexto de la región sur del estado.

Palabras claves: Federal FM, historia oral, radialistas, radio.

\begin{abstract}
Radio Federal FM is linked to the Federal University of Pelotas and was the first educational radio station in a modulated frequency channel in Rio Grande do Sul. In its 36 years of existence, a brief story was told at the official website. The research for this article is the first phase of a historiographical work that intends to cover the history of the Radio from the broadcaster perspective and the transformations and chalenges with the new

\footnotetext{
${ }^{1}$ Mestranda em História; Programa de Pós-Graduação em História da Universidade Federal de Pelotas; Pelotas; Rio Grande do Sul; Brasil; sissamoreira@gmail.com. Trabalho apresentado no III Encontro Humanístico Multidisciplinar e II Congresso Latino-Americano de Estudos Humanísticos Multidisciplinares, Jaguarão/RS, Brasil, 2017.
} 
technologies, as well as the daily impact that is part of the process of the history of federal FM. The study presents a methodology of oral history, in its thematic aspect, besides documentary and printed sources. The testimonies, narratives And memories of those who participated and/or participate in the group of professionals of the radio station reveal some elements of the history and the development of the radio, in the context of the southern region of the state.

Keywords: Federal FM, oral history, broadcaster, radio.

\section{Introdução}

O rádio surgiu em 1896, com a criação do primeiro aparelho do mundo por Guglielmo Marconi, um físico e inventor italiano, que revolucionou a comunicação. Contudo, as primeiras emissoras surgiram após a Primeira Guerra Mundial, em 1920, nos Estados Unidos. No Brasil, os serviços radiofônicos foram inaugurados em 1922, no Rio de Janeiro. Já a primeira emissora, surgiu em 1923. Deste então, ocorreram várias modificações na área.

Em Pelotas, a Sociedade Rádio Pelotense, primeira rádio do interior do Rio Grande do Sul, foi fundada em 1925 por um grupo de amigos. A Rádio Pelotense, atualmente, é a mais antiga rádio em funcionamento (FERRARETTO, 2002).

$\mathrm{Na}$ Universidade Federal de Pelotas, a ideia de ter uma rádio educativa foi fomentada após a sua criação, em 1969. A instituição recebeu a concessão para atuar com uma emissora em 1977. Nomeada Rádio Cosmos, iniciou suas transmissões experimentais em 1980, mas a inauguração oficial somente veio a acontecer no ano seguinte, em 8 de janeiro de 1981. Em 1993, por decisão do Conselho Universitário, passou a ser chamada de Rádio Federal FM, a primeira emissora de caráter educativo a funcionar em canal de frequência modulada no Rio Grande do Sul.

Entre as modificações relevantes na história do rádio, podemos citar a inserção da publicidade, o desenvolvimento do transistor, o advento do telefone fixo e do celular, as unidades móveis, a consolidação da internet e o advento da televisão que, segundo MAGNONI (2013), acabou levantando várias previsões pessimistas sobre o futuro desse meio de comunicação de massa.

Confrontados com tantas alterações, tornou-se necessário para os radialistas desafiarem-se, adaptando sua rotina de trabalho, sendo às vezes necessário, o estabelecimento de novas práticas, objetivando a sobrevivência a novos tempos e novas tecnologias.

Cada nova tecnologia inserida no cotidiano do rádio acaba transformando todos os processos de trabalho, além de aumentar a qualidade do conteúdo e, muitas vezes, alterar o formato e ampliar as formas de interação com o público. 
Novas tecnologias, abordagens conceituais e demandas do público surgidas e ou consolidadas na primeira década do século XXI fizeram que o rádio se modificasse em alguns aspectos, embora suas características básicas tenham sido mantidas. $\mathrm{O}$ cenário de atuação profissional, no entanto, de fato se alterou. Técnicas e tecnologias empregadas evoluíram. (FERRARETTO, 2014, p.13)

Atualmente, o rádio está passando por uma grande transformação através da internet e suas novas plataformas que possibilitaram a adesão a novos suportes de recepção. Hoje podemos ouvir emissoras de todo o mundo no celular, na TV, no computador entre outras tecnologias que permitem a conexão. Para Ferraretto (2014, p. 17), "no início da década de 2000, tornou-se ultrapassada a ideia de radiodifusão como conceito dominante em rádio e em televisão."

Este trabalho apresentará os resultados parciais da pesquisa de dissertação do Mestrado do Programa de Pós-Graduação em História da Universidade Federal de Pelotas, que trata da história do rádio, tendo como base a Rádio Federal FM, as modificações pelas quais o meio de comunicação passou e como o ofício de radialista foi impactado por essas mudanças, fazendo com que o rádio se mantenha como veículo de comunicação até hoje. A análise se dará, principalmente, a partir dos depoimentos, narrativas e memórias dos radialistas da Rádio Federal FM, além da análise de fontes documentais e impressas. A metodologia de História Oral, em sua versão temática foi escolhida devido a possibilidade de revelação do cotidiano dos profissionais entrevistados, como afirma Alberti que "a entrevista de história oral permite também recuperar aquilo que não encontramos em documentos de outra natureza: acontecimentos pouco esclarecidos ou nunca evocados, experiências pessoais, impressões particulares etc.” (ALBERTI, 2000, p.22).

Dessa forma, a partir de um estudo focado nas adaptações do ofício de radialistas da Rádio Federal FM a cada novidade no cenário da radiodifusão, a pesquisa possibilita entender de que maneira os profissionais contribuíram para que o rádio ainda se sustente como um meio de comunicação.

\section{Um breve relato sobre as transformações do Rádio no Brasil}

Os serviços radiofônicos no País foram inaugurados oficialmente em 07 de setembro de 1922, no Rio de Janeiro, com um discurso do presidente Epitácio Pessoa por ocasião da abertura da Exposição Internacional, a qual celebrava o centenário da Independência do Brasil. Em 1923 foi fundada, por Roquette Pinto e Henry Morize, a Rádio Sociedade do Rio de Janeiro, primeira emissora no Brasil com transmissões regulares, sendo em 1936 doada ao 
Ministério da Educação, chamando-se atualmente Rádio MEC (JUNG, 2013). Conforme registros:

Naquela época, as tecnologias eram outras. Não se realizavam reportagens de campo, grandes transmissões ou radiojornais com a participação ao vivo de repórteres espalhados pelo país. Tratava-se das transmissões de Roquette Pinto, um jornal marcado e os comentários sobre as principais notícias do dia. (LOPEZ, 2010, p.402).

No Brasil, segundo Calabre (2002), até a década de 1950, ano em que a televisão começou a chegar aos lares brasileiros, o rádio cumpriu o papel social de promover uma integração da sociedade para além dos limites físicos, rompendo a barreira da comunicação, mesmo com os altos índices de analfabetismo do País, por se tratar de um veículo sonoro. A partir deste período, o rádio tornou-se mais acessível à população.

Em termos de modificações relevantes na história do rádio no Brasil podemos citar a inserção da publicidade, a partir do Decreto $\mathrm{n}^{\circ}$ 21.111, de primeiro de março de 1932, assinado pelo presidente Getúlio Vargas, tornando o rádio um veículo comercial de fato.

Uma das maiores crises vivenciadas pelo rádio foi o surgimento da televisão, um novo meio de comunicação que, além de contratar os profissionais do rádio e imitar os quadros das principais emissoras, também captou grande parte dos recursos em publicidade que antes eram destinados a eles. Para Briggs e Burke (2016, p.16): "Cada produto básico deixa sua marca, e a mudança para novos produtos invariavelmente traz períodos de crise". Desta forma, segundo Ortriwano (1985), o rádio precisou buscar uma linguagem mais econômica, diminuir seus investimentos em produção e equipamentos e as emissoras passaram a rodar mais músicas e dedicar-se às necessidades regionais e grupos específicos de ouvintes.

A obra também deve se concentrar na mudança, em lugar da continuidade, embora se lembre aos leitores de quando em quando que, ao se introduzirem novas mídias, as mais antigas não são abandonadas, mas ambas coexistem e interagem. Com o surgimento das publicações, os manuscritos continuaram sendo importantes, como aconteceu com os livros e o rádio na idade da televisão. (BRIGGS e BURKE, 2016, p.15)

Cabe aqui também destacar o desenvolvimento do transistor, em 1947, o qual trouxe um novo papel para a radiodifusão, sobretudo na relação entre o ouvinte e a mídia, revolucionando a produção e a recepção da transmissão por meio do rádio. Segundo Ferraretto (2001), essa nova tecnologia permitiu a alteração da fonte de alimentação de aparelhos de rádio, tornando-os portáteis e facilitando sua presença na rotina dos ouvintes. Em consonância, Prata (2008) descreve os benefícios que essa tecnologia propiciou para os 
radialistas, os quais passaram a contar com a possibilidade de deslocamento, essencial para o surgimento das reportagens de campo, tornando a invenção do transistor uma das inovações mais significativas do rádio naquela época.

Outras tecnologias também contribuíram para a agilidade e evolução do rádio como a popularização do telefone fixo, na década de 1970, e, mais tarde, o surgimento do celular, na década de 1990, o qual possibilitou uma liberdade maior para o radialista, especialmente nas coberturas in loco, intensificando-as.

Surgiram, também, as Unidades Móveis que facilitaram a mobilidade e os gravadores magnéticos que facilitaram as edições de conteúdo. Antes disso, as primeiras tentativas de reportagens de rua, utilizaram equipamentos pesados e de difícil transporte. Da mesma forma, estes recursos possibilitaram um grande aumento da interação dos ouvintes na programação das emissoras, o que antes era realizado a partir do envio de cartas. A programação do rádio passou a ter um viés muito mais voltado aos acontecimentos locais.

Há de destacar-se também a introdução de sistemas multimídia no Brasil, em meados da década de 1990, os quais alteraram a natureza do rádio, questionando a validade da definição desse veículo e a sua comunicação. A Internet apresenta-se, no momento, como um suporte complementar para as emissões em FM. Para o rádio, a Internet pode ser uma concorrência, um desafio ou uma aliada, destacando-se como uma nova ferramenta, visto a variedade que o mundo online oferece. Ao pensarmos na relação destes dois meios, deve-se considerar os aspectos que os caracterizam e que influenciam a forma como o rádio potencia a estrutura da sua comunicação (CORDEIRO, 2004). Tal pensamento converge para Neuberger (2012), para quem o rádio está sempre buscando novas saídas para as dificuldades que vão surgindo ao longo dos seus quase 90 anos de existência no Brasil. Quando se pensa que não há mais sobrevida para o veículo, ele ressurge das próprias tecnologias, que poderiam sufocálo enquanto veículo de comunicação.

As novas tecnologias e a informatização substituem antigos processos de trabalho, muitas vezes manuais, deslocando-os para as máquinas. Confrontado com tantas alterações, tornou-se necessário para os radialistas desafiarem-se adaptando sua rotina de trabalho, sendo necessário, às vezes, estabelecer novas práticas, a fim de sobreviver a novos tempos e novas tecnologias.

\section{A Rádio Cosmos}

A Rádio Federal FM, prefixo ZYD 579 e frequência 107,9 FM, funciona a partir da Universidade Federal de Pelotas (UFPel) e foi a primeira emissora de caráter educativa em 
canal de Frequência Modulada no Rio Grande do Sul (FONSECA, 2007). Na época de sua criação, já existiam rádios educativas no Rio Grande do Sul, porém em Amplitude Modulada como mostra Zuculoto (2015):

\begin{abstract}
A primeira foi a Rádio da Universidade Federal do Rio Grande do Sul, uma AM inaugurada oficialmente em 1957, em Porto Alegre, capital gaúcha. Outra AM universitária deste período é a da Universidade Federal de Santa Maria, no município do mesmo nome, igualmente no Rio Grande do Sul (ZUCULOTO, 2015, p.71).
\end{abstract}

Inicialmente, a emissora atingia as cidades de Pelotas, Capão do Leão, Canguçu, Morro Redondo, São Lourenço do Sul, Piratini, Turuçu, Pedro Osório, Rio Grande, Arroio do Padre, Pinheiro Machado, Candiota, Arroio Grande, Hulha Negra, Jaguarão, Bagé, São José do Norte, Mostardas, Tavares, Santa Vitória do Palmar e Santana da Boa Vista. Atualmente, o transmissor perdeu potência e alcança apenas algumas cidades próximas à Pelotas. A Rádio Federal FM também pode ser sintonizada via internet, no endereço do seu website e em outros aplicativos de Rádio.

A liberação da transmissão ocorreu com a Portaria 953, em 14 de setembro de 1977, emitida pelo Departamento Nacional de Telecomunicações (Dentel), do Ministério das Comunicações. O instrumento legal outorgava permissão à Universidade Federal de Pelotas para estabelecer, sem direito de exclusividade, uma estação de radiodifusão sonora em frequência modulada, com fins exclusivamente educativos, sob a denominação de Rádio Cosmos.

Em notícia do Diário Popular, do dia 22 de setembro de 1977, o jornal destacava a concessão da Rádio como um sonho do primeiro reitor da UFPel, Delfim Mendes da Silveira, que administrou a instituição até o final de 1977. Sendo assim, a responsabilidade de montar a infraestrutura da emissora ficou para o reitor Ibsen Wetzel Stephan, que esteve à frente da Reitoria entre os anos de 1977 a 1981. Em consonância com a notícia do periódico, o fundador e primeiro diretor da Rádio, José Maria Marques da Cunha, em sua narrativa, conta que o mérito da criação da Rádio foi do reitor Delfim, que lutou por anos para que a Universidade tivesse uma emissora de radiodifusão, “o que ele queria era que a própria Universidade pudesse fazer cursos a distância e pudesse auxiliar a comunidade mais carente. Ele escolheu o nome da rádio, com o nome de Rádio Cosmos” (CUNHA, 2017).

Inicialmente, a Rádio Federal FM era vinculada a Pró-Reitoria de Extensão e Cultura, entretanto, em 1993, quando recebeu a atual nomenclatura, passou a lotação para a 
Coordenação de Comunicação Social da Universidade, por decisão do Conselho Universitário.

De acordo com Ferraretto (2007), em 1972, a Rádio Itaí FM, iniciou suas transmissões em Porto Alegre. Já em Pelotas, a primeira FM foi a Rádio Alfa, inaugurada em 1979. Em sua narrativa, o jornalista Roberto Engelbrecht, que foi diretor da rádio de 1993 a 2013, destaca que em Pelotas o rádio, em Frequência Modulada, chegou tardiamente.

Só para veres o atraso da coisa aqui para nós. Em 1974, o pai comprou um FM para ouvir a Itaí, depois entrou a Gaúcha e a Guaíba, em 1974 se ouvia lá, já tinha FM e aqui foi entrar em 1980. [...] mas só para ter uma ideia, lá em Porto Alegre, em 1974, os caras já tinham rádio que estavam transmitindo na grande Porto Alegre ali e para nós aqui, só em 1980 foi a primeira. (ENGELBRECHT, 2017).

De acordo com uma notícia veiculada no Diário Popular do dia 5 de junho de 1980, a Rádio Federal FM passaria a transmitir a programação em caráter experimental no dia 15 de junho de 1980. Já nas informações que constam no website da Rádio Federal FM, a então Rádio Cosmos iniciou suas transmissões experimentais em agosto de 1980. Engelbrecht relata uma série de dificuldades neste período de implantação da emissora, o que justifica a diferença de datas verificada no Diário Popular e no website da instituição. De acordo com o radialista o parque de transmissões inicial, por ter um alcance pequeno, precisou ser removido do campus Capão do Leão e instalado em Pelotas:

[...] foi instalado no campus com um transmissor de 50 watts FM, cedido pela Escola Técnica na época, e do campus não chegava na cidade, então nós precisávamos colocar ela na cidade em outro lugar de melhor alcance, usando o mesmo transmissor, porque o transmissor Harris que está até hoje no ar, não tinha chegado em Pelotas ainda (ENGELBRECHT, 2017).

A notícia do Diário Popular também detalha a situação técnica da emissora em seu início. De acordo com o periódico, a Rádio Cosmos iniciou as transmissões com um transmissor de baixa potência, 500 watts, que cobria apenas a cidade de Pelotas. Esta condição ocorreu até a chegada do Sistema Irradiante Gates ao Brasil, que, segundo a notícia, se daria em outubro de 1980.

Engelbrech explica que atualmente as rádios comunitárias funcionam com 25 watts, o que demonstra o baixo alcance do transmissor utilizado na fase inicial da Rádio. A Portaria $\mathrm{n}^{\circ}$ 4334, de 17 de setembro de 2015, do Ministério das Comunicações, que dispõe sobre o serviço de radiodifusão comunitária, permite que uma Rádio Comunitária tenha uma potência efetivada irradiada de no máximo 25 watts, que permite a transmissão do sinal para um raio 
de mil metros apenas. Já o transmissor definitivo da Rádio tinha uma potência de dez mil watts.

O jornalista destaca que a antena precisou ser instalada no alto do prédio da Faculdade de Odontologia para que o sinal pudesse ser sintonizado em Pelotas, porém este ainda era fraco. Em sua fala, é possível notar as dificuldades que a equipe passou para conseguir colocar a emissora no ar.

O engenheiro da PUC, bolou uma antena diferente, só que tinha de apanhar essa antena em Porto Alegre e trazer para cá. Eu me lembro que eu tinha ido a Canela, tinha ido em casa e o Cunha (diretor da Rádio) pediu para passar em Porto Alegre para pegar a antena. Eu tinha um fusca, a antena era um pouco maior que o fusca, e tinha que trazer em cima do carro e eu trouxe. (ENGELBRECHT, 2017)

Passado o período de experimentações, a Rádio Cosmos teve sua inauguração oficial no dia 08 de janeiro de 1981. A equipe que iniciou os trabalhos da Rádio Cosmos era coordenada pelo diretor José Marques da Cunha e foi composta pelo locutor Cleber Luiz Zurchimitten, falecido em março de 2016, o operador Francisco Luis da Silva Magalhães, também falecido, o operador Giovani Mendes da Silva, o técnico Luiz Virgílio Lopes Padilha, o discotecário Paulo de Oliveira Mancini, falecido em agosto de 2016, o locutor Roberto Gustavo Engelbrecht e o técnico Rudinei Tellier de Freitas.

De acordo com a cobertura da inauguração publicada pelo Diário Popular, no dia 9 de janeiro de 1981, a inauguração da Rádio Cosmos teve a presença do reitor Ibsen Wetzel Stephan e do reitor da Universidade Católica de Pelotas, Carlos Alberto de Souza Vianna, que acionaram o transmissor. O diretor da emissora, José Marques da Cunha, falou sobre o caráter educativo-cultural da Rádio Cosmos, o pioneirismo e o trabalho a ser realizado integrado à comunidade. O pró-reitor de Extensão, José Passos Magalhães, realizou um breve relato das ações para a conquista da Rádio e salientou o protagonismo do então reitor Ibsen Wetzel Stephan.

Um dos principais problemas que surgiram após a inauguração, foi a localização no campus Capão do Leão. Engelbrecht lembra que as correspondências destinadas à Rádio chegavam sempre com atraso. Muitas vezes os convites chegavam após o evento ocorrer, o que impedia a participação da emissora e a divulgação do evento. Além disso, a dificuldade do transporte e a distância de Pelotas dificultava a participação de convidados nos programas. Engelbrecht destaca também que a localização impedia que ela funcionasse em determinados horários. 
$\mathrm{O}$ caráter experimental dela foi $2 \mathrm{~h}$ de manhã, $2 \mathrm{~h}$ de tarde e $2 \mathrm{~h}$ de noite. Nós nos dividíamos os sete, dois de manhã, dois de tarde e dois de noite, e o discotecário preparava a programação para tocar durante o período. Ela iniciou tocando das sete à meia noite, até porque sempre teve o problema de transporte no campus. (ENGELBRECHT, 2017)

Cabe ressaltar que o município de Capão do Leão foi emancipado em 1982 e está localizado a cerca de $20 \mathrm{~km}$ de distância de Pelotas. Com isso, na época, além da distância, a Rádio da Universidade Federal de Pelotas passou a ter a sua sede fora da cidade a qual a sua instituição pertencia. Cunha também faz referência aos problemas gerados pela distância de Pelotas, segundo o ex-diretor "a rádio funcionava das sete da manhã até a meia noite [...] porque naquela época tinha falta de pessoal e não era informatizada, precisava de um operador para operar a rádio" (CUNHA, 2017).

Engelbrecht também relatou alguns problemas com a instalação do transmissor definitivo. Segundo ele, a UFPel precisou construir uma casa para o equipamento. Porém, a obra ocorreu em uma área alagadiça do campus Capão do Leão e a construção sofreu várias infiltrações que resultaram em muitas avarias nos equipamentos.

A válvula queimava de seis em seis meses [...]. Qual era o problema no transmissor? [...] quando foi feita a casinha, fizeram um buraco embaixo do transmissor de onde vinham os cabos de energia e som do estúdio e era um buraco de 60 por 60 , de um metro de profundidade, num banhado, sempre cheio de água. (ENGELBRECHT, 2017)

Segundo o jornalista, os problemas foram resolvidos pelos próprios trabalhadores da Rádio que construíram uma tubulação acima do solo para passar os cabos.

Sobre a programação inicial da Rádio, Engelbrecht destacou os programas Chorinhos e Chorões, Clássicos em FM, As Orquestras da Cosmos, Você faz o Programa e Federal Pesquisa, Drops Cultural, Dicas de Cinema e o BR 107 que tocava músicas nativistas intercaladas com informações sobre o trânsito na Zona Sul, ao vivo, por telefone, direto da Polícia Rodoviária Federal. O programa Chorinhos e Chorões teve grande destaque na época e culminou com a gravação, nos estúdios da então Rádio Cosmos, do único disco de Avendano Júnior, em 1983. Na capa do LP consta um agradecimento à equipe da emissora. O pelotense cavaquinista Avendano Júnior foi um grande intérprete e compositor de Choro.

Nascendo com o propósito de ser um veículo educativo e cultural, a rádio também carrega a responsabilidade de informar. Segundo Engelbrecht, a programação da Rádio desde o seu início contou com programas jornalísticos: 
Teve durante muitos anos jornalismo do que estava acontecendo na Instituição. Teve um período de jornal, perto do meio dia e repetia esse jornal no final da tarde. Atinente a jornalismo também, teve um programa sobre a história da música. (ENGELBRECHT, 2017).

Como lembra Zuculoto (1998), esta perspectiva esteve presente no Rádio desde a sua implementação por Roquette Pinto, ao criar a Rádio Sociedade. Ele idealizou um veículo que não apenas informasse ou oferecesse entretenimento, mas que interpretasse os fatos. Cabe aqui ressaltar que a programação de veículos públicos educativos tem uma finalidade educativa e cultural. Nessa perspectiva, o que o diferencia dos outros veículos é o conteúdo. Segundo a produtora cultural da Rádio Federal FM, aposentada, Vera Lopes, as discussões em torno da função social de uma rádio educativa sempre estiveram presentes. Entre as questões discutidas pela equipe, Lopes ressalta algumas: “A rádio educativa só toca música? Ela faz o que além disso?” (LOPES, 2017).

Mendell (2011) destaca alguns princípios centrais para definir a radiodifusão pública, entre eles, a liberdade de expressão que permite que as informações fluam livremente, dando manutenção aos direitos humanos. Para o autor, "a liberdade de expressão tem uma natureza dual, uma vez que ela protege não apenas o direito de comunicar informações e ideias (o direito do emissor), mas também os direitos de buscar e receber informações e ideias (os direitos do receptor)" (MENDELL, 2011, p.11).

A pluralidade e a diversidade também são características que devem permear o fazer rádio educativo. Os ouvintes devem ter acesso à diferentes interpretações e análises.

É por terem disponível um leque de pontos de vista que os indivíduos podem exercitar a plena cidadania, escolhendo entre perspectivas concorrentes, à medida que se engajam no processo de tomada de decisões públicas. Em relação à radiodifusão, as ondas de rádio são um recurso público e devem ser usadas em benefício do público como um todo, incluindo as visões ou os interesses das minorias. (MENDELL, 2011, p. 19)

Zuculoto (1998), ao analisar as programações das rádios públicas, pontua a tendência do tempo pioneiro das rádios de tocarem música clássica e erudita em suas programações. A autora atribui a este fato, a causa das dificuldades no desenvolvimento e popularização do rádio. Para ela, a escolha do gênero erudito se deu em função do público do rádio na época, que era composto por uma elite intelectual e econômica. Zuculoto destaca a contradição entre a programação musical escolhida e o objetivo da radiodifusão pública de ter a função social de levar educação, informação e cultura à população. Vera Lopes, também argumenta sobre as escolhas de estilos musicais que devem ser tocados em uma rádio educativa. 
[...] então a rádio educativa não pode tocar pop, não pode rock, ela toca música de qualidade. Tá, e qual é a música de qualidade? Eu tenho as minhas músicas preferidas, que tem um elemento mais sofisticado, mais ligado com determinadas tendências, mas isso não significa que seja o monopólio da rádio educativa... Naquela época a preocupação era divulgar o 'lado B' do disco, divulgar uma coisa que não mereceu a atenção da mídia... (LOPES, 2017)

Dentro da programação inicial da Rádio Cosmos, a maior parte do tempo era dedicada à música que, segundo Engelbrecht, tinha como carro chefe a música clássica, a ópera e a MPB. Em alguns horários, a música era acompanhada por comentários que contavam a história da composição, dos autores e dos músicos que a interpretavam.

\begin{abstract}
Antes, às $8 \mathrm{~h}$ da noite entrava música orquestrada e depois a partir das $10 \mathrm{~h}$ (da noite) já era clássica. E sábado tocava ópera. Mas essa parte educativa da rádio, sempre se tocou clássico, ópera, fazendo a narrativa de quem é, qual é a história daquela música, daquele compositor, ou até mesmo da orquestra que está apresentando. (ENGELBRECHT, 2017)
\end{abstract}

Contudo, nota-se dentro da programação inicial da Rádio Federal FM, programas de utilidade pública, alguns voltados à disseminação do conhecimento produzido dentro da Universidade. Apesar dos diferenciais oferecidos ao ouvinte dentro da programação da emissora, os entrevistados afirmam que a audiência da Rádio nunca foi alta. Engelbrecht destaca a dificuldade de se atingir todos os públicos.

A audiência sempre foi baixa, nunca foi boa. Teve algumas vezes de pegar pesquisa, pesquisa sempre foi uma dificuldade, para pagar não tinha como. Eu acompanhei algumas pesquisas que eram feitas pela Católica, pela Alfa e é o tipo de coisa que eu não acredito nem na pesquisa que foi feita para eles, porque mostrava a Alfa em primeiro, a Atlântida em segundo... a Pampa e depois nós. [...] conversa mole para boi dormir, história... porque sempre foi difícil essa história de fazer rádio para todos, todo mundo, não tem, não existe isso. Rádio é segmento, é segmentada (ENGELBRECHT, 2017).

Como já citado anteriormente, o rádio educativo deve ter como características principais, a pluralidade, a diversidade e a liberdade de expressão. Neste sentido, a audiência das rádios públicas se dá de forma diferente da rádio comercial, que visa o lucro. Nos veículos públicos, a responsabilidade é de oferecer um conteúdo diferenciado e de qualidade ao maior número de pessoas possível. Lopes (2017) acredita que as escolhas musicais não justificam a baixa audiência, mas sim o fato de não ter conseguido ser atrativa e interessante. $O$ jornalista aposentado da Rádio Federal FM, Luiz Carlos Vaz, explica que durante os primeiros anos da rádio, não havia como transmitir ao vivo, o fato se deve a "preocupação, ainda durante a ditadura militar, que uma rádio que transmitisse ao vivo pudesse fazer subversão" (VAZ, 
2017). Segundo o jornalista, somente em 1984 tornou-se possível as transmissões ao vivo. Para Lopes, esta característica inicial da Rádio Federal FM, foi uma das causadoras da baixa audiência.

[...] eu acho que sempre o grande encalhe foi a rádio gravada. E aí o gravado se confundiu, primeiro porque nós somos uma rádio educativa e nós não podemos errar no português, nós não podemos errar no ao vivo, quer dizer, tem que ser gravado porque tem que sair perfeito... e isso aí, por si só congela, já tira o ímpeto do rádio. Porque rádio em última instância é conversa, ela tem que ser coloquial. (LOPES, 2017)

Vera Lopes, ingressou na Universidade em janeiro de 1983, como produtora cultural com a responsabilidade de cumprir um contrato da Rádio com o Sistema Nacional de Rádios Educativas - Sinred, que tinha o objetivo de produzir uma programação regional a ser distribuída entre as rádios educativas do País. O Sinred foi extinto na década de 1990. O programa produzido tinha o nome de Meu Brasil Brasileiro e tinha a finalidade de divulgar peculiaridades das diversas cidades e regiões do País.

Em sua narrativa, fica claro o carinho e o orgulho que Lopes tem do programa que ajudou a conceber, principalmente da edição que foi premiada pela Rádio MEC, emissora sede do Sinred. O programa teve como tema a camisa canarinho desenhada pelo jaguarense Aldyr Schlee e contou com a participação do professor da Faculdade de Agronomia Eliseu Maciel da UFPel, José Antônio Duarte da Silva, que fez parte da seleção brasileira vestindo a camisa canarinho no pan-americano de 1956, disputado no México.

E um dos programas que nós fizemos que foi muito bem-sucedido e foi considerado um dos cinco melhores daquele ano foi o da camisa canarinho, porque juntou uma série de coincidências. O fato de ela ter sido desenhada pelo Schlee, que ele já não aguenta mais (risos), mas foi... e o fato de que um dos primeiros jogadores que usaram aquela camisa canarinho, integrantes de uma equipe daqui do Rio Grande do Sul que representou o Brasil no pan-americano, era o Duartão. Ele era o capitão da equipe, já era formado em Agronomia e, depois deixou a vida de jogador de futebol tornou-se um professor da Agronomia, o professor José Antônio Duarte da Silva. Ele era o capitão da equipe, então aquela equipe tinha mais gente... eu não sei... eu sei que eu entrevistei, para fazer esse programa, passagens com o Schlee, passagens com o Duartão, enfim, a gente compôs o programa e foi considerado muito bem sucedido e uma boa locução, isso em (19)84. (LOPES, 2017)

A segmentação do rádio ocorreu com o advento da televisão, as emissoras precisaram adaptar a programação com o objetivo de aumentar a sua audiência que estava em queda e passaram a produzir conteúdo voltado para públicos específicos, bem como para regiões específicas. Para Ferraretto (2014, p. 14), não há como impor um padrão para o rádio por se tratar de um meio dinâmico, "é inevitável que possua uma série de particularidades de acordo 
com o segmento que visa atingir". Lopes salienta que em 2013, quando assumiu a direção da Rádio, decidiu assumir a política de integração com o Mercosul que estava sendo implantada no Brasil pelo governo, "a intenção deles sempre foi de unificar a América Latina e para nós aqui a coisa estava dada, porque nós somos essa nação do Pampa... a intenção era fazer da nossa programação um painel que mostrasse a diversidade e as identidades da cultura dos povos do Mercosul" (LOPES, 2017).

O desenvolvimento de novas tecnologias contribuiu para que os radialistas desenvolvessem uma nova forma de fazer rádio. A operação da rádio em si era muito complicada. Segundo César (2005), o locutor precisava colocar discos no ponto, operar os cartuchos, cassetes e fitas rolo simultaneamente. Em sua fala, Engelbrecht cita que tudo era cronometrado e que o operador precisava calcular o tempo da música para ir ao banheiro e voltar a tempo, por exemplo. Sobre como era realizado o trabalho dos radialistas antes dos computadores, o entrevistado explica que:

\begin{abstract}
Antes era gravação em fita rolo, em cartucho... O cara gravava em cartucho... [...] O cartucho enrolava sobre si mesmo a própria fita, de um lado saia, do outro lado entrava, quando tu terminavas de fazer o teu projeto, cinco seis cartuchinhos estavam prontos com o teu serviço do dia inteiro. (...) Fora as edições, como é que eram... o corte de uma música... o cara pegava no cabeçote, acertava o cabeçote e passava a caneta, marcava, puxava para fora, pegava o estilete, cortava atravessado, colava com Durex... (...) assim se fazia uma edição... coisa que hoje em dia, tu fazes em segundos, pega o mouse, carrega ali e tá... (ENGELBRECHT, 2017).
\end{abstract}

A locutora da Rádio Federal FM, Maria Alice Estrella, destaca as dificuldades que este trabalho manual "eu gravei quatro horas de música e a fita estava suja e não gravou, então no momento em que eu levei ao operador de áudio e ele colocou no aparelho para rodar a fita, ele olhou para mim e disse: mas não tem gravação nenhuma” (ESTRELLA, 2017).

Com a chegada do computador, os antigos equipamentos de rádio foram deixados de lado e uma nova rotina de trabalho dentro da rádio surgia. Da máquina de escrever ao computador, da edição manual à edição digital, nascia uma produção mais prática e instantânea. Briggs e Burke (2016) defendem que os computadores fizeram com que todos os tipos de serviços "tomassem novas formas". César (2005) descreve o trabalho no estúdio, atualmente, como sendo mais compacto, simples e racionalizado. Para ele, o tempo que sobra a partir das novas tecnologias é utilizado para atender os ouvintes de forma mais interativa. Em sua fala, Estrella descreve as facilidades na rotina de trabalho da rádio, a partir do uso do computador. "E hoje é tudo por computador, já vai direto da mesa que eu gravo, já vai para o 
programa, já vai para a rede, já está no ar e aleluia...”. Engelbrecht lembra da aquisição do primeiro computador pela Rádio Federal FM:

A adaptação do uso do computador na Rádio foi muito lenta, pela distância do campus, até os caras colocarem a fibra ótica lá... que se pode ter acesso... antes era só um computador que tinha. A tal ponto que o primeiro computador que a Rádio rodou com um só programa de rádio instalado no computador. Então eles tiveram que comprar o computador, tela... tudo. A Universidade comprou. Isso em 94... 95 acho que foi. Sabe quanto foi pago por esse computador? Eu nunca mais me esqueci, tinha um valor quebrado, mas foram 15 mil reais. [...] naquela época um computador IBM que tu tivesses em casa estava na faixa de uns quatro mil, mais ou menos. (ENGELBRECHT, 2017)

O radialista também relata as mudanças ocorridas na produção dos programas com o advento do telefone celular que contribuiu para facilitar a mobilidade do rádio e aumentar a sua instantaneidade. Desta forma, o rádio passou a estar mais presente no local dos acontecimentos e a passar as informações de forma mais rápida.

Eu saia com uma extensão da rádio de moto, quando antes eu teria que levar... [...] tinha uma maleta de transmissão (...) tinha as entradas de microfone, tinha saídas de fone de ouvido, tudo com potenciômetro para cada uma e nós solicitávamos uma linha para a companhia instalar no que nós queríamos transmitir (...) na linha telefônica nós plugávamos essa maleta e fazíamos a transmissão para a rádio (ENGELBRECHT, 2017).

Em seus relatos, Lopes também lembra da inserção do celular. A produtora destaca que antes precisava levar um gravador com fita cassete para fazer as entrevistas externas, mas que a chegada do aparelho celular facilitou o seu trabalho. Além disso, atenta para o atraso da chegada das tecnologias na Rádio Federal FM.

Eu ia com um tijolaço para a feira do livro e entrevistava os autores, lá no banco direto para a rádio... deve ter demorado um pouquinho, não era tão rápida a rádio assim, mas lá por 1995, 1997, te garanto que eu já estava lá na Feira do Livro, num banquinho, sem o gravador, mas com aquela nova invenção, um negócio fantástico. (LOPES, 2017)

Outra grande tecnologia que influenciou no processo de se fazer rádio, pontuada pelo entrevistado, foi a internet. Ela possibilitou uma maior interação com os ouvintes, agregou à produção radiofônica, facilitando a busca de informações e serviu como um novo suporte ao rádio, com a criação da radioweb. Briggs e Burke (2016) acreditam que, na história social da mídia, não se pode tratar a Internet como o clímax, mas como um período que teve diversos caminhos. No entanto, os autores citam que: 
[...] no final da década de 1990 E.M. Noam, então diretor do Instituto para Teleinformação da Universidade de Colúmbia, afirmou que, "quando for escrita a história da mídia do século XX, a Internet será vista como sua maior contribuição" (BRIGGS e BURKE, 2016, p.300, grifos dos autores).

Do computador, passando pelos telefones celulares, até a internet, todas as novas tecnologias geraram grandes mudanças no ofício de radialistas. Para Beck (2011), o processo de modernização deve gerar uma reflexão, por ser ao mesmo tempo um tema e um problema.

\footnotetext{
Mais urgente do que nunca precisamos de esquemas de interpretação que nos façam - sem nos lançar equivocadamente à eterna velha novidade, repleta de saudades e bem relacionada com as discretas câmaras do tesouro da tradição - repensar a novidade que nos atropela e que nos permita viver e atuar com ela. (BECK, 2011, p.14)
}

Os estúdios ficaram menores, as mídias foram digitalizadas, equipamentos diminuíram de tamanho e os profissionais passaram a desempenhar outras funções dentro da emissora.

\begin{abstract}
A utilização das novas tecnologias permite obter ganhos, em termos de eficiência de custos, de capacidade de resposta às variações da procura, de produtividade, de qualidade e de inovação. No entanto, a realização dessas potencialidades depende do desenvolvimento de formas organizacionais, competências e comportamento capazes de utilizar as novas tecnologias de modo eficaz. As novas tecnologias criam novas oportunidades, mas ao mesmo tempo, requerem uma nova lógica organizacional. (KOVÁCS, 2001, p. 46)
\end{abstract}

Aos poucos os processos de trabalho foram sendo adaptados ou substituídos por outros, algumas funções que antes eram manuais, foram mecanizadas ou informatizadas. A exemplo da função de discotecário de Rádio, extinta com a evolução dos novos suportes de música que tornaram as mídias físicas como o LP e o CD, obsoletas, muitas outras funções também foram extintas ou reestruturadas.

\title{
3. Conclusões
}

Preservar a memória do passado de uma instituição torna possível a compreensão dos períodos anteriores, da identidade e da cultura institucional, além dos processos de trabalho que envolvem os seus colaboradores.

De acordo com Candau (2001, p.61), “através da memória o indivíduo capta e compreende continuamente o mundo, manifesta suas intenções a esse respeito, estrutura-o e coloca-o em ordem, conferindo-lhe sentido".

Ao longo de sua história, o Rádio foi tornando-se cada vez mais acessível, como um veículo de comunicação inclusivo. Soma-se a isso, o fato de ser mais acessível 
financeiramente do que os outros meios de comunicação e por ultrapassar limites geográficos e até nacionais.

A cada tecnologia que surgia, o cotidiano dos trabalhadores do Rádio foi se alterando. Nota-se um aumento na qualidade dos serviços prestados como um todo, uma maior interação com os ouvintes, mas também alterações nos processos de trabalho, que podem trazer problemas aos trabalhadores por terem que se adaptar.

Todas essas mudanças marcam profundamente o perfil do ofício de radialista, extinguindo algumas funções, como o discotecário, e modificando outras, como o locutor que passou a ter novos papéis. O profissional de rádio está em constante reformulação e transformação, criando novos processos com a finalidade de dar conta das novas tecnologias. Na Rádio Federal FM, a realidade mostra-se a mesma. Esse fato fica evidente ao se analisar as memórias dos radialistas que ajudaram a fundar e construir a emissora.

As memórias ajudam na compreensão das adaptações pelas quais os trabalhadores passaram. Para além das transformações do oficio de radialista, foi possível perceber grandes dificuldades da emissora, como uma rádio educativa, não comercial, em encontrar sua essência e pensar sua programação. Analisando os relatos, percebe-se os grandes problemas que a equipe precisou resolver para implementar e manter a Rádio Federal FM funcionando durante os seus 36 anos de história. Esses aspectos são muito marcantes em todas as lembranças do entrevistado.

A busca por informações sobre a Rádio Federal FM, através da história oral, possibilitou o acesso a fatos muito importantes para a análise da história da emissora. Esses acontecimentos certamente não seriam encontrados em outros tipos de fontes e possibilitaram reconstituir um pouco da programação, da concepção e do desenvolvimento da emissora.

Dentro dos conceitos trabalhados por Alberti (2000), as memórias relatadas pelo radialista, possibilitaram reconstituir algumas práticas cotidianas da profissão e suas evoluções, bem como a memória institucional.

Através dos relatos, percebe-se que a Rádio Federal FM não acompanhou a evolução normal pela qual passaram as rádios comerciais, principalmente por ser um veículo público, com poucos recursos e, desta forma, por não ter a possibilidade de captar recursos publicitários. No entanto, percebe-se que, embora tardiamente, o desenvolvimento da emissora reflete as mesmas adaptações e dificuldades pelas quais as outras rádios passaram de acordo com os autores citados.

Da mesma forma, fica evidente também as alterações no ofício de radialista dentro da Rádio Federal FM, uma profissão que está em constante reformulação e transformação, 
criando novos processos com a finalidades de dar conta das novas tecnologias de comunicação.

\section{Referências}

CUNHA, José Maria Marques. Radialista. Entrevista concedida a Silvana de Araújo Moreira. Realizada na radioweb do entrevistado, Pelotas, outubro de 2017.

ENGELBRECHT, Roberto Gustavo. Jornalista. Entrevista concedida a Silvana de Araújo Moreira. Realizada na casa do entrevistado, Pelotas, agosto de 2017.

ESTRELLA, Maria Alice. Radialista. Entrevista concedida a Silvana de Araújo Moreira. Realizada na casa da entrevistada, Pelotas, agosto de 2017.

LOPES, Vera. Diretora de Produção aposentada. Entrevista concedida a Silvana de Araújo Moreira. Realizada na casa da entrevistada, Pelotas, outubro de 2017.

VAZ, Luiz Carlos. Jornalista. Entrevista concedida a Silvana de Araújo Moreira. Realizada no Mercado Público de Pelotas, Pelotas, agosto de 2017.

Jornal Diário Popular. 22 de setembro de 1977. Acervo da Biblioteca Pública Pelotense.

Jornal Diário Popular. 05 de junho de 1980. Acervo da Biblioteca Pública Pelotense.

Jornal Diário Popular. 09 de janeiro de 1981. Acervo da Biblioteca Pública Pelotense.

<http://pelotascultural.blogspot.com.br>. Acesso em: 25 de setembro de 2017.

<http://www.anatel.gov.br/legislacao/normas-do-mc/915-portaria-4334>. Acesso: em 25 de setembro de 2017.

<https://www.jusbrasil.com.br/diarios/3314743/pg-33-secao-1-diario-oficial-da-uniao-doude-20-09-1977/pdfView> . Acesso: em 23 de outubro de 2016.

<wp.ufpel.edu.br/federalfm/>. Acesso em: 23 de outubro de 2016.

$<$ http://terceirotempo.bol.uol.com.br/que-fim-levou/duarte-867>. Acesso em 25 de setembro de 2017.

ALBERTI, Verena; FERNANDES, Tania Maria; FERREIRA, Marieta de Morais (Org's). História oral: desafios para o século XXI. Rio de Janeiro: Editora Fiocruz, 2000.

BECK, Ulrich. Sociedade de Risco: rumo a uma outra modernidade. São Paulo: Editora 34, 2011.

BRIGGS, Asa; BURKE, Peter. Uma história social da mídia: de Gutenberg à Internet. Rio de Janeiro: Zahar, 2016.

CALABRE, Lia. A Era do Rádio. Rio de Janeiro: Jorge Hazar Ed., 2002. 
CANDAU, Jöel. Memória e identidade. São Paulo: Contexto, 2011.

CÉSAR, Cyro. Rádio: a mídia da emoção. São Paulo: Summus, 2005.

CORDEIRO, Paula. Rádio e Internet: novas perspectivas para um velho meio. In: II Congresso Ibérico de Ciências da Comunicação-II IBÉRO. 2004. Disponível em: http://www.bocc.ubi.pt/pag/cordeiro-paula-radio-internet-novas-perspectivas.pdf.

FERRARETTO, Luiz Artur. Rádio no ar: o veículo, a história e a técnica. Porto Alegre: Sagra Luzzato, 2001.

FERRARETTO, Luiz Artur. Rádio no Rio Grande do Sul (anos 20, 30 e 40): dos pioneiros às emissoras comerciais. Canoas: Ed. Da ULBRA, 2002.

FERRARETTO, Luiz Artur. Rádio e Capitalismo no Rio Grande do Sul: as emissoras comerciais e suas estratégias de programação na segunda metade do século 20. Canoas: Editora Ulbra, 2007.

FERRARETTO, Luiz Artur. Rádio: teoria e prática. São Paulo: Summus, 2014.

FONSECA, Vicente Fernandes Dutra. Rádios universitárias federais gaúchas: um estudo da programação jornalística. 2007. Trabalho de Conclusão de Curso (Curso de Comunicação Social: Habilitação em Jornalismo) - Faculdade de Biblioteconomia e Comunicação, Universidade Federal do Rio Grande do Sul, 2007.

JUNG, Milton. Jornalismo de rádio. 4. ed. São Paulo: Contexto, 2013.

KOVÁCS, Ilona. Empresa flexível: problemas sociais pós-taylorismo. In: SANTOS. Maria João et alii. Globalizações: novos rumos no mundo do trabalho. Florianópolis/Lisboa: UFSC, 2001, p.43-68.

LOPEZ, Débora Cristina. Aproximações dos níveis convergência tecnológica em comunicação: um estudo sobre o rádio hipermidiático. In: FERRARETTO, Luiz Arthur (org.). E o rádio? Novos horizontes midiáticos. Porto Alegre: Edipucrs, 2010.

MAGNONI, Antonio Francisco; RODRIGUES, Kelly De Conti. O rádio e a adaptação à nova era das tecnologias da comunicação e informação: contextos, produção e consumo. Anais IX Encontro Nacional da História da Mídia: GT História da Mídia Sonora. Ouro Preto, v.9, n.1, p. 1-15, 2013.

MENDELL, Toby. Serviço público de radiodifusão: um estudo de direito comparado. Brasília: UNESCO, 2011.

NEUBERGER, Rachel Severo Alves. O rádio na era da convergência das mídias. Editora UFRB, 2012.

ORTRIWANO, Gisela Swetlana. A informação no rádio - os grupos de poder e a determinação dos conteúdos. São Paulo: Summus, 1985.

PRATA, Nair. Webradio: Novos Gêneros, Novas Formas De Interação. Tese. Belo horizonte: Faculdade de Letras da UFMG, 2008. 
ZUCULOTO, Valci. O rádio público no Brasil: resgate histórico e transformações contemporâneas das rádios Nacional e MEC do Rio de Janeiro. CECS-Publicações/eBooks, p. 65-82, 2015. Disponível em:

http://www.lasics.uminho.pt/ojs/index.php/cecs_ebooks/article/view/2145/2063

ZUCULOTO, Valci. A notícia no radiojornalismo brasileiro: transformações históricas e técnicas. Dissertação (Mestrado em Comunicação Social) - Faculdade de Comunicação, Pontífica Universidade Católica do Rio Grande do Sul, Porto Alegre, 1998. 